\title{
Bioactive compounds and fruit quality traits of Vesuvian apricot cultivars (Prunus armeniaca L.) and use of skin cover colour as a harvesting index
}

\author{
Claudio Di Vaio ${ }^{1}$, Chiara Cirillo ${ }^{1 *}$, Antonio Pannico ${ }^{1}$, Giulia Graziani $^{2}$, Alberto Ritieni ${ }^{2}$, Franco Famiani ${ }^{3}$ \\ ${ }^{1}$ Università degli Studi di Napoli Federico II, Dipartimento di Agraria, Via Università, 100 - 80055 Portici (NA), Italy \\ ${ }^{2}$ Università degli Studi di Napoli Federico II, Dipartimento di Farmacia, Via Domenico Montesano, 49 - 80131 Napoli, \\ Italy \\ ${ }^{3}$ Università degli Studi di Perugia, Dipartimento di Scienze Agrarie Alimentari e Ambientali, Borgo XX Giugno, 74 - \\ 06121 Perugia, Italy
}

*Corresponding author: chiara.cirillo@unina.it

Abstract

The qualitative/nutritional characteristics of apricots mainly depend on cultivar, cultivation area and ripening stage. Thus, it is important to characterise different cultivars and harvest fruits at the optimum time. There is no conclusive evidence about harvesting indexes in apricot for decision making about the best harvesting time. Moreover, little is known about fruit qualitative/nutritional characteristics of autochthonous cultivars of the Campania region (Italy), mainly grown in the area of Vesuvius volcano. Therefore, fruit attributes of the Vesuvian cultivars Ceccona, Vitillo, and Pellecchiella were evaluated during ripening with the aim of characterizing the qualitative/nutritional value of the fruit and specifying a reliable harvesting index. Cultivar, picking time and skin cover colour affected all the fruit qualitative/nutritional attributes considered. For the first time, a number of minor phenolic compounds were quantified in apricot. Ceccona was the richest in phenolic compounds, while Pellecchiella had the highest trolox equivalent antioxidant capacity (TEAC). During ripening, the TEAC decreased on a per-gram basis and increased on a per-fruit-basis. Cultivar, picking time and skin cover colour had a great influence in determining the qualitative/nutritional value of the apricots, and overall Pellecchiella showed the best characteristics. The skin cover colour percentage may be a suitable harvesting index for the traditional Vesuvian apricot cultivars. A comprehensive description of the phenolic compounds and a dilution effect on apricot fruit TEAC is reported for the first time.

Keywords: Antioxidant activity, bioactive compounds, fruit quality, germplasm, Prunus armeniaca L.

Abbreviations: DW_dry weight; FF_flesh firmness; FW_fresh weight; SSC_soluble solids content; TA_titratable acidity; TEAC_Trolox equivalent antioxidant capacity;

Introduction

Apricot (Prunus armeniaca L.) is an important fruit tree of temperate world regions, where it is highly appreciated for its delicious edible fruit. It is enjoyed as fresh fruit, but apricots are also canned, dried, frozen, and used as baby food. Other products include wine, brandy, jam, marmalade, nectar, pulp, jelly, etc. (Janatizadeh et al., 2008). Generally, apricots have an important place in human nutrition (Dauchet and Dallongeville, 2008). Owing to their contents of several nutritious and health-promoting bioactive and nutraceutical compounds such as sugars (mainly glucose, fructose and sucrose), organic acids (mainly malic, citric and quinic acids) (Schmitzer et al., 2011), phenolics, flavonoids, anthocyanins, carotenoids, dietary fibre, minerals and vitamins, they are considered a functional food, beneficial to consumer health and disease risk reduction (Leccese et al., 2007; 2010; 2012; Hegedüs et al., 2010; 2011).

In the last decades apricot cultivation in the main European producing countries, such as Italy, France and Spain, has experienced a significant turnover of cultivated varieties. In fact, local varieties have often been replaced, partly or totally, by new cultivars that are preferred for their productivity and fruit quality (Piagnani et al., 2013). New commercial cultivars are distinguished by their large fruit size, orange colour of the skin, intense blush and high firmness, and slow softening flesh that facilitates shipping and handling. In many cases, however, improvement of the technological characteristics occurs to the detriment of the flavour (taste and aroma), causing consumer dissatisfaction: consumers are attracted by the aesthetic features but are disappointed by the poor eating quality. In a recent comprehensive review on fruit and vegetable quality, Kyriacou and Rouphael (2018) highlighted how consumers, in the last few years, have become sensitive to a marketdriven concept of quality, since products arrive at their tables through long supply chains. In contrast, in some cases, supporting alternative short supply chains might enable consumer satisfaction to be reclaimed by re-evaluating traditional fruit varieties. Southern regions of Italy, such as 
the area of Vesuvius volcano in Campania, are the main apricot-growing areas of the country and they are among the most important in Europe. The Campania with a surface of over 4.100 hectares has an apricot production that exceeds 64 thousand tons (ISTAT, 2017). Although traditional varieties are still in use, as stated above, varietal renovation has been occurring in recent years to meet new market requirements and mainly satisfy industry demands. Fideghelli and Della Strada (2010) reported that from 1980 to 2007563 new apricot cultivars plus 61 hybrids (apricot $x$ plum, plum $\times$ apricot) had been listed in the National register of cultivated varieties.

Apricots are appreciated by consumers for their characteristic flavour, sweetness and juiciness. They have a rapid physiological evolution with fast quality shifts and organoleptic characteristics that are closely related to the variety and ripening/harvesting stage (Dragovic-Uzelac et al., 2007). The phytochemicals in the fruits have beneficial effects on human metabolism, such as antioxidant, antiinflammatory and immune-stimulating ones (Madrau et al., 2009). Among the phytochemicals, phenolic compounds, such as chlorogenic acid, rutin, catechin and epicatechin, are predominant.

The content of phenolic compounds in apricots can be affected by a number of agronomical/environmental (variety, climatic conditions, ripening stage, etc.) (Ruiz and Egea, 2008) and technological (harvest and postharvest treatments, storage and processing conditions, etc.) factors, and, in general, it is positively correlated with their antioxidant capacity (Scalzo et al., 2005).

As stated above, fruit quality greatly depends on ripening stage and, in order to specify the best harvesting time, the ripeness indices generally used are skin ground colour, soluble solids content, flesh firmness, titratable acidity, etc., but often they are not well codified and little information is available on their possible interrelationships and the possibility of using other ones as main indices. More knowledge on this would be very useful in order to improve specification of the best harvesting time in relation to the maturation stage.

A large number of studies have been carried out to characterize the quality, composition and biochemistry (Bassi and Selli, 1990; Guerreri et al., 2001; Drogoudi et al., 2008; Lo Bianco et al., 2010; Mratiniü et al., 2011; Baldicchi et al., 2015; Famiani et al., 2017) of apricots belonging to the list of new cultivars, accessions and clones released and cultivated in the last years, whereas very little has been done on the quality attributes of autochthonous/traditional varieties of the Campania region. This is surprising because, in spite of the fact that apricot cultivation in Italy and Campania has been subjected to a significant cultivar turnover, traditional varieties are still widely cultivated and appreciated.

The main aim of this study was to evaluate the main quality attributes, including total antioxidant activity and total polyphenol content, of the fruits of some of the most cultivated autochthonous apricot cultivars of the Campania region, which could also be important for breeding purposes. This is important because the consumer is becoming more and more willing to pay more for an apricot that has both a high quality taste and a high nutraceutical value. Moreover, a secondary aim is specification of ripening/harvesting indexes and definition of possible interrelationships among them in order to better define the harvesting time of the fruit according to the desired qualitative characteristics.

\section{Results and Discussions}

\section{Fruit qualitative traits and total antioxidant capacity}

The fruit qualitative traits, reported in Table 1, indicated significant differences in the main effects of cultivar, pickings and skin cover colour. Among the cultivars, Vitillo showed the highest fruit fresh weight (FW), but the lowest titratable acidity (TA) and intermediate soluble solids content (SSC). Pellecchiella had the highest flesh firmness (FF), high SSC and intermediate TA. Ceccona showed the lowest SSC and the highest TA and, as a result of this, a very low SSC/TA ratio. The general effect of picking on fruit traits was also significant, with decreasing fruit FW, FF and TA from the first to the third picking, whereas the SSC and the SSC/TA ratio increased. On the contrary, the time of picking did not affect the Trolox equivalent antioxidant capacity (TEAC) (Table 1). Also, skin cover colour affected all other fruit characteristics. Fruits with the highest percentage of cover colour (> 65\%) showed the highest FW and SSC and the lowest FF, TA and TEAC.

ANOVA showed significant interactions among the factors considered. In particular, fruit FW, SSC and FF varied significantly with the interactions among cultivar, picking time and fruit skin colour $(\mathrm{Cv} \times \mathrm{P} \times \mathrm{C})$ (Table 1). Indeed $\mathrm{cv}$ Vitillo had the highest FW at the second picking for both skin colour $>65 \%$ and $65-35 \%$ and at the third picking only for the most coloured fruits (Fig. 1), whereas the lowest FW was when the skin colour was $<35 \%$ in fruits of both the Pellecchiella harvested at the first picking and Vitillo harvested at the third picking (Fig. 1). The highest values of SSC were in the fruits $>65 \%$ skin coloured of Pellecchiella harvested at the third picking, whereas the lowest was in the less coloured $(<35 \%)$ fruits of Ceccona harvested at pickings 1 and 2 (Fig. 2). On the contrary, the highest FF was measured in low coloured fruits $(<35 \%)$ of Pellecchiella harvested at the first picking and the lowest in the most coloured $(>65 \%)$ fruits of Ceccona and Vitillo at the last picking (Fig. 3). The TA of the fruit juice was affected significantly by the interaction between the cultivar and picking $(C \times P)$ (Table 1$)$, with Ceccona and Pellecchiella having the highest TA at first and second pickings (average $29 \mathrm{~g} \mathrm{~L}^{-1}$ malic acid) and at the first picking $\left(28.68 \mathrm{~g} \mathrm{~L}^{-1}\right.$ malic acid), respectively, whereas the lowest TA of the fruit juice was recorded for Vitillo harvested at the third picking (18.83 $\mathrm{g} \mathrm{L}^{-1}$ malic acid). Also, the SSC/TA ratio was significantly influenced by the $C \times P$ interaction (Table 1 ), ranging from the highest value in Vitillo and Pellecchiella at the third picking $(\approx 1)$ to the lowest in Ceccona at the second and last picking (nearly 0.5 ).

Data of the qualitative traits highlighted the variability of the characteristics of the different cultivars as well as between their maturity stages, related both to the pickings and to the extension of skin cover colour. The three cultivars belong to a larger group of autochthonous apricot cultivars having an intermediate/slightly late ripening time (Lo Bianco et al. 2010). Pellecchiella had the highest SSC in the highly coloured fruit (cover colour $>65 \%$ ) in all three pickings, likely 
Table 1. Fruit characteristics: fruit fresh weight (FW), soluble solids content (SSC), flesh firmness (FF), titratable acidity (TA), SSC/TA ratio and Trolox Equivalent Antioxidant Capacity (TEAC). Means followed by different letters are significantly different for $P \leq 0.05$.

\begin{tabular}{|c|c|c|c|c|c|c|}
\hline Cultivar & $\begin{array}{l}\mathrm{FW} \\
(\mathrm{g})\end{array}$ & $\begin{array}{l}\text { SSC } \\
\left({ }^{\circ} \text { Brix }\right)\end{array}$ & $\begin{array}{l}\mathrm{FF} \\
(\mathrm{N})\end{array}$ & $\begin{array}{l}\text { TA } \\
\text { ( } \mathrm{g} \mathrm{L}^{-1} \text { malic acid) }\end{array}$ & SSC/TA & $\begin{array}{l}\text { TEAC } \\
\left(\mu \mathrm{mol} \mathrm{TE} \mathrm{g}{ }^{-1} \mathrm{FW}\right)\end{array}$ \\
\hline \multicolumn{7}{|l|}{ Cultivar (Cv) } \\
\hline Ceccona & $68.21 \mathrm{~b}$ & $9.99 \mathrm{c}$ & $34.43 \mathrm{~b}$ & $19.64 \mathrm{a}$ & $0.49 b$ & $1.57 \mathrm{~b}$ \\
\hline Vitillo & $72.93 \mathrm{a}$ & $12.20 \mathrm{~b}$ & $31.68 \mathrm{~b}$ & $14.23 \mathrm{c}$ & $0.88 a$ & $1.29 \mathrm{c}$ \\
\hline Pellecchiella & $68.11 \mathrm{~b}$ & $14.08 \mathrm{a}$ & $54.69 a$ & $16.81 \mathrm{~b}$ & $0.89 a$ & $1.68 \mathrm{a}$ \\
\hline \multicolumn{7}{|l|}{ Picking (P) } \\
\hline 1 & $70.01 \mathrm{ab}$ & $11.74 \mathrm{c}$ & $45.57 \mathrm{a}$ & $18.03 \mathrm{a}$ & $0.66 c$ & $1.55 \mathrm{a}$ \\
\hline 2 & $71.11 \mathrm{a}$ & $12.03 \mathrm{~b}$ & $42.55 b$ & $17.05 \mathrm{~b}$ & $0.74 b$ & $1.49 \mathrm{a}$ \\
\hline 3 & $68.01 \mathrm{~b}$ & $13.76 \mathrm{a}$ & $32.84 \mathrm{c}$ & $13.58 \mathrm{c}$ & $1.06 \mathrm{a}$ & $1.46 \mathrm{a}$ \\
\hline \multicolumn{7}{|c|}{ Cover colour (C) } \\
\hline$>65 \%$ & $74.96 \mathrm{a}$ & $13.65 \mathrm{a}$ & $30.13 \mathrm{c}$ & $14.92 \mathrm{c}$ & $0.95 a$ & $1.45 \mathrm{~b}$ \\
\hline $65-35 \%$ & $71.65 \mathrm{~b}$ & $12.41 \mathrm{~b}$ & $42.78 \mathrm{~b}$ & $16.88 \mathrm{~b}$ & $0.76 \mathrm{~b}$ & $1.49 \mathrm{ab}$ \\
\hline$<35 \%$ & $63.22 c$ & $10.99 \mathrm{c}$ & $50.86 a$ & $17.86 \mathrm{a}$ & $0.66 \mathrm{c}$ & $1.57 \mathrm{a}$ \\
\hline \multicolumn{7}{|l|}{ ANOVA } \\
\hline $\mathrm{Cv}$ & $* * *$ & $* * *$ & $* * *$ & $* * *$ & $* * *$ & $* * *$ \\
\hline$P$ & $* *$ & $* * *$ & $* * *$ & $* * *$ & $* * *$ & NS \\
\hline c & $* * *$ & $* * *$ & $* * *$ & $* * *$ & $* * *$ & NS \\
\hline $\mathrm{Cv} \times \mathrm{P}$ & $* * *$ & $* *$ & $* * *$ & $* * *$ & $*$ & $* * *$ \\
\hline $\mathrm{Cv} \times \mathrm{C}$ & $* *$ & NS & $* * *$ & NS & NS & $* * *$ \\
\hline $\mathrm{P} \times \mathrm{C}$ & NS & $* *$ & $*$ & NS & NS & NS \\
\hline $\mathrm{Cv} \times \mathrm{P} \times \mathrm{C}$ & $* * *$ & $*$ & $* * *$ & NS & NS & NS \\
\hline
\end{tabular}

TEAC, antioxidant capacity measured as micromoles of 6-hydroxy-2,5,7,8-tetramethylchromane-2-carboxylic acid equivalent per gram of fresh weight.

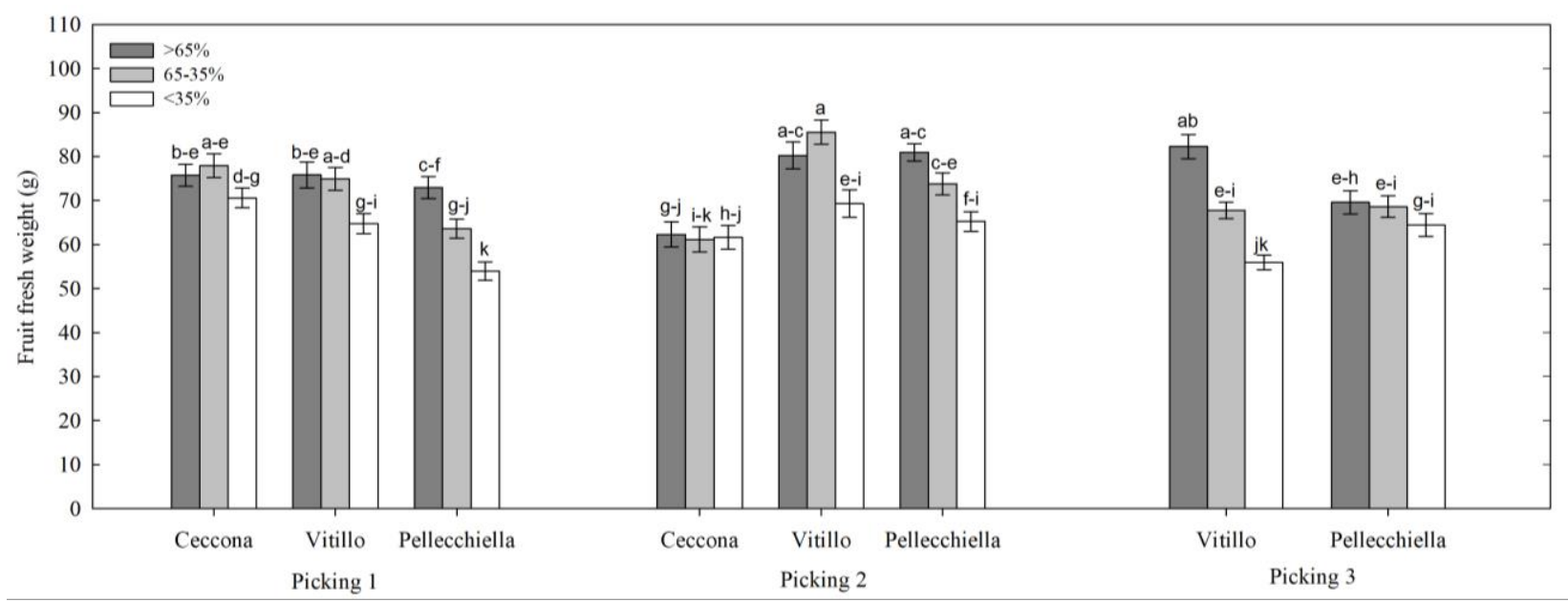

Fig 1. Fresh weight of apricot fruits of the cultivars Ceccona, Pellecchiella and Vitillo harvested at two or three different pickings. Means followed by different letters are significantly different for $P \leq 0.05$. 
Table 2. Contents/composition of phenolic compounds in the flesh of apricot fruits. For each parameter, means followed by different letters are significantly different for $P \leq 0.05$.

\begin{tabular}{|c|c|c|c|c|c|c|c|c|c|c|}
\hline Cultivar & $\begin{array}{l}\Sigma \quad \text { phenolic } \\
\text { compounds } \\
\left(\mu \mathrm{g} \mathrm{g}^{-1} \mathrm{FW}\right)\end{array}$ & $\begin{array}{l}\text { Chlorogenic acid } \\
\left(\mu \mathrm{g}^{-1} \mathrm{FW}\right)\end{array}$ & $\begin{array}{l}\text { Catechin } \\
\left(\mu \mathrm{g} \mathrm{g}^{-1} \mathrm{FW}\right)\end{array}$ & $\begin{array}{l}\text { Epicatechin } \\
\left(\mu \mathrm{g} \mathrm{g}^{-1} \mathrm{FW}\right)\end{array}$ & $\begin{array}{l}\text { Hyperoside } \\
\left(\mu \mathrm{g} \mathrm{g}^{-1} \mathrm{FW}\right)\end{array}$ & $\begin{array}{l}\text { Kaempherol-3-rutinoside } \\
\left(\mu \mathrm{g} \mathrm{g}^{-1} \mathrm{FW}\right)\end{array}$ & $\begin{array}{l}\text { Narcissin } \\
\left(\mu \mathrm{g} \mathrm{g}^{-1} \mathrm{FW}\right)\end{array}$ & $\begin{array}{l}\text { Naringenin } \\
\left(\mu \mathrm{g} \mathrm{g}^{-1} \mathrm{FW}\right)\end{array}$ & $\begin{array}{l}\text { Procyanidin B2 } \\
\left(\mu \mathrm{g} \mathrm{g}^{-1} \mathrm{FW}\right)\end{array}$ & $\begin{array}{l}\text { Rutin } \\
\left(\mu \mathrm{g} \mathrm{g}^{-1} \mathrm{FW}\right)\end{array}$ \\
\hline Ceccona & $389.93 \mathrm{a}$ & $144.34 \mathrm{a}$ & $111.56 \mathrm{a}$ & $83.09 a$ & $0.365 c$ & $0.590 \mathrm{c}$ & $2.768 \mathrm{a}$ & $0.041 \mathrm{a}$ & $41.58 \mathrm{a}$ & $5.589 \mathrm{~b}$ \\
\hline Vitillo & $184.36 \mathrm{~b}$ & $102.52 \mathrm{~b}$ & $19.12 \mathrm{~b}$ & $20.30 \mathrm{~b}$ & $0.691 \mathrm{a}$ & $3.706 a$ & $1.826 \mathrm{c}$ & $0.040 a$ & $6.376 b$ & $29.77 a$ \\
\hline Pellecchiella & $131.35 \mathrm{~b}$ & $70.02 c$ & $15.43 \mathrm{~b}$ & $16.01 \mathrm{~b}$ & $0.463 \mathrm{~b}$ & $2.496 \mathrm{~b}$ & $1.575 b$ & $0.038 \mathrm{~b}$ & $0.406 c$ & $24.83 a$ \\
\hline ANOVA & $* * *$ & $* * *$ & $* * *$ & $* * *$ & $* * *$ & $* * *$ & $* * *$ & * & $* * *$ & $* * *$ \\
\hline
\end{tabular}

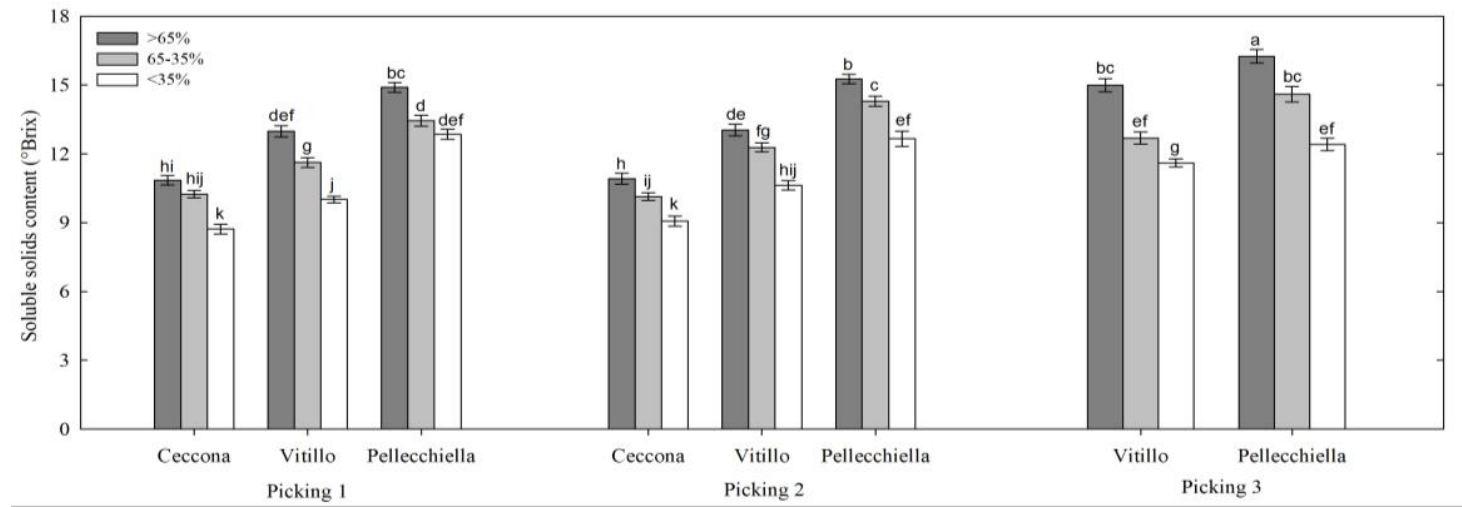

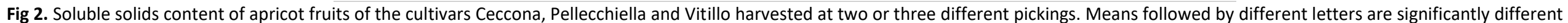
for $P \leq 0.05$.

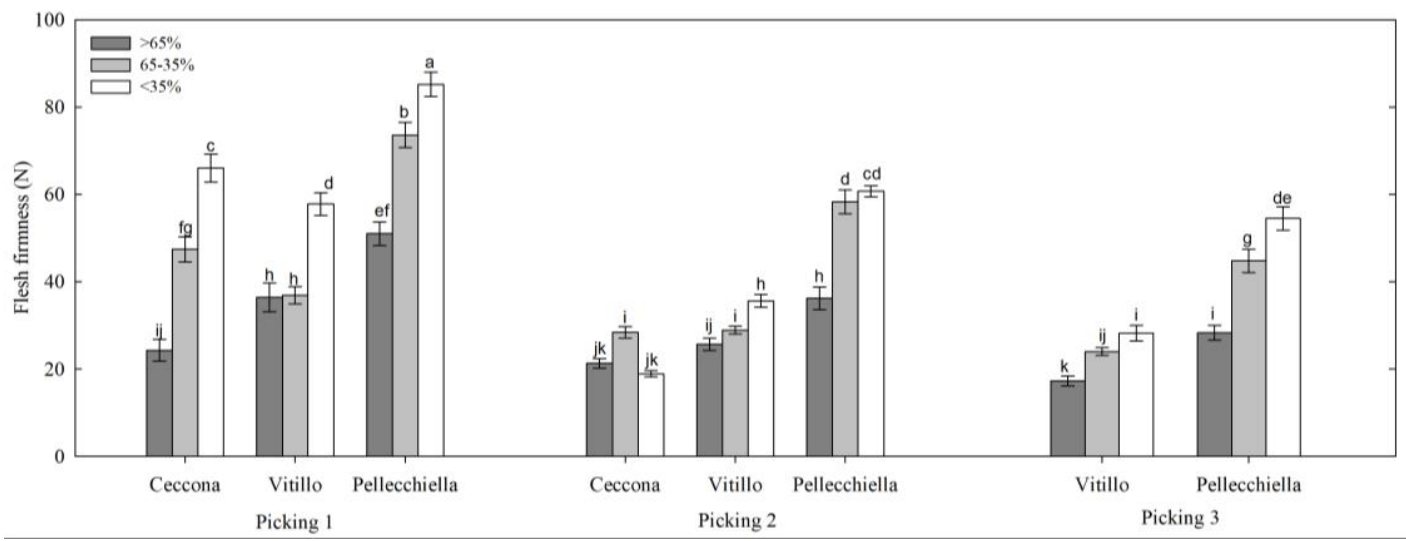

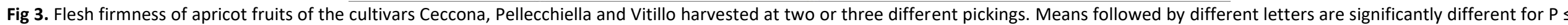
0.05 . 


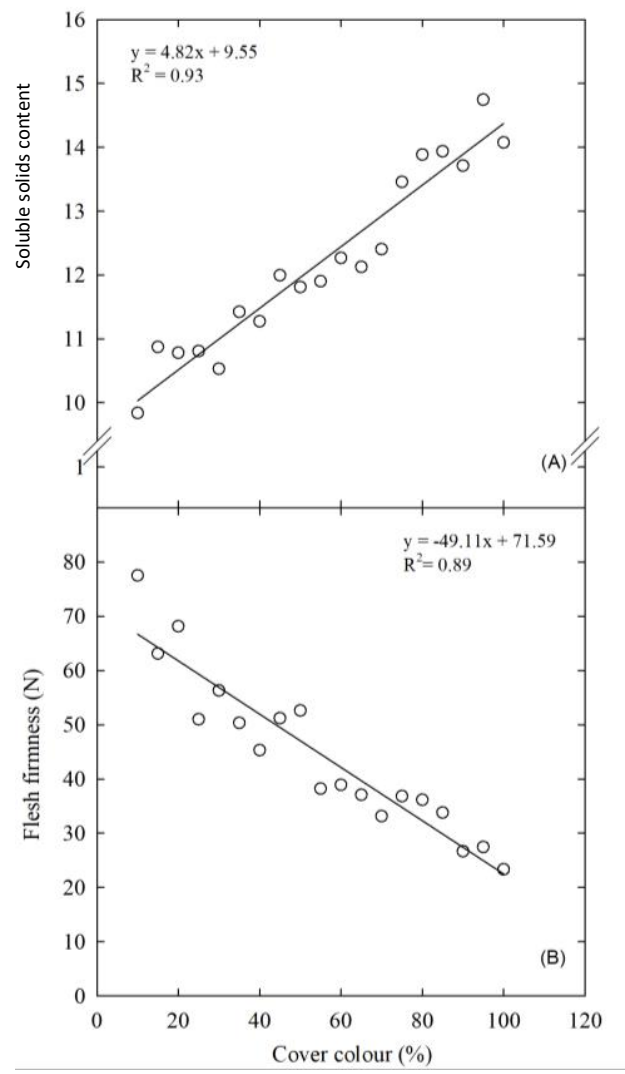

Fig 4. Relationships between the skin cover colour and soluble solids content (A) and flesh firmness (B) in apricot fruits of the cultivars Ceccona, Pellecchiella and Vitillo.

because it is the latest ripening among the three cultivars and, as a result, there was more time to accumulate sugars (Leccese et al., 2010, Basile et al., 2005). Furthermore, this cultivar also had the highest FF in all three cover colour classes (Table 1, Fig. 3). These fruit quality traits of Pellecchiella have contributed to keeping it on the list of the valuable Italian cultivars suitable for Southern growing areas (Lo Bianco et al., 2010). In addition, Pellecchiella also had the highest TEAC, which was comparable to the highest values of other cultivars reported in the literature (Leccese et al., 2007; 2010).

Significant linear relationships were found between the skin cover colour, expressed as percentage of coloured fruit surface, and the soluble solids content (SSC) and fruit flesh firmness (FF) ( $R^{2}=0.93$ and 0.89 for SSC and FF, respectively) (Fig. 4). This indicates that in apricot the cover colour extension percentage is highly correlated to fruit ripening stages. Up to now, studies have regarded the possibility of using the skin ground colour as harvesting index for stone fruits (Delwiche and Baumgardner, 1985; Basile et al., 2005; Luchsinger et al., 1998), but there are not evidences for the use of the cover colour as an index for apricots. Therefore, to the best of our knowledge, this is the first evidence which indicates the possibility of using the skin cover colour, which is very easy to estimate also visually, as a main ripening index for apricot varieties that have a progressive appearance of red cover colour on fruits during ripening, such as the traditional apricot cultivars. Indeed, in these apricots, fruit ripening is strictly associated with both the skin ground colour turning from green to yellow and red and its progressive extension. This is very important because the skin cover colour extension can be easily estimated for each single fruit and makes it very simple to select, at each picking, the fruits which have the desired degree of ripening. The total antioxidant capacity was significantly different for the three apricot cultivars (Table 1). Pellecchiella and Vitillo had the highest and lowest values, respectively. These values were higher than those reported for peaches and lower than for plum (Scalzo et al., 2005; Contessa et al., 2013). Also, the ripening stage affected the TEAC (Table 1). The values decreased with increase in ripening. However, it is interesting to note that during ripening, from the skin cover colour of $<35 \%$ to $>65 \%$, the fruit weight increased about $19 \%$ and TEAC decreased about $8 \%$. Thus, the decrease in TEAC could be due to a dilution effect as a result of fruit growth and there could be a synthesis instead of a degradation of compounds responsible for TEAC.

Also for TEAC there were interactions among the factors considered. In particular, for Pellecchiella the fruits harvested at the first picking had the highest values (1.76 $\mu \mathrm{mol}$ TE $\mathrm{g}^{-1} \mathrm{FW}$ ), whereas those of Vitillo had the lowest ones at all the pickings (on average $1.29 \mu \mathrm{mol} \mathrm{TE} \mathrm{g}^{-1} \mathrm{FW}$ ).

\section{Fruit polyphenolic compounds}

The UHPLC analysis of the extracts obtained from apricot flesh showed three main groups of phenolic compounds readily identified by their distinctive UV spectra. The phenolic content/composition of apricot is mainly due to some bioactive compounds, mainly belonging to the three groups of procyanidins such as procyanidin B2, hydroxycinnamic acid derivatives such as chlorogenic acid, and flavonols, such as catechin, epicatechin and rutin among the most abundant compounds (Ruiz et al., 2005). This study showed a number of chromatographic peaks with characteristic UV spectra of these three groups of compounds in the chromatograms (e.g. cultivar Ceccona, Supplementary materials Fig. 1). However, to obtain additional insight into the number of molecules contributing to the phenolic component of the apricot fruit, a quantitative characterization of the phenolic compounds in the fruits of the three cultivars was performed by HRMS. For the metabolites identified, the retention times and the theoretical and experimental molecular mass with an accuracy of $<5 \mu \mathrm{g} \mathrm{g}^{-1}$ for all the samples analysed are listed in Supplementary materials Table 1 . Ceccona had the highest amount in total phenolic compounds $\left(389.93 \mu \mathrm{g} \mathrm{g}^{-1}\right.$ FW), followed by Vitillo (184.36 $\mathrm{g} \mathrm{g} \mathrm{g}^{-1} \mathrm{FW}$ ) and Pellecchiella (131.35 $\mathrm{g} \mathrm{g} \mathrm{g}^{-1} \mathrm{FW}$ ) (Table 2). Chlorogenic acid was always the most abundant compound, accounting for a percentage with respect to the total amount of polyphenols of $37 \%, 53 \%$ and $55 \%$ in Ceccona, Pellecchiella and Vitillo, respectively. The chlorogenic acid content in the flesh of apricot has been reported (Ruiz et al., 2005) to be higher in white or pale yellow flesh selections/cultivars and this could explain the highest amount found in Ceccona (Mattatelli et al., 2003). Also the other major components of the polyphenolic compounds, such as catechin, epicatechin, procyanidin B2 and narcissin, were higher in Ceccona (Table 2). These compounds were similar in the other two cultivars (e.g. catechin, epicatechin) or intermediate in Vitillo and lower in Pellecchiella (e.g. narcissin, procyanidin B2). In a detailed 
work on the polyphenolic compounds in the peel and flesh of several apricot genotypes catechin and epicatechin were always very low (Ruiz et al., 2005), whereas they were high in the three cultivars in the present study. In fact they were very high in Ceccona. On the contrary, rutin was high in both Vitillo and Pellecchiella, and 5/6 fold lower in Ceccona (Table 2). It is known from the literature that the rutin content in fruit may be useful for counteracting hypertension and other circulatory system diseases (Wang et al., 2011). The relevant amounts found in Vitillo and Pellecchiella, higher than the levels reported in the literature for apricots, may lead to considering their beneficial nutritional value in the human diet. The contents of hyperoside and kaempherol-3rutinoside were relatively low in Ceccona compared to the other two cultivars (Table 2). To the best of our knowledge, this is the first identification and quantification of hyperoside, kaempherol-3-rutinoside, narcissin and naringenin in apricots. The finding that Ceccona showed a relatively higher amount of catechin (28\% of the total polyphenol content) compared to Pellecchiella and Vitillo, which barely reached values of $10-11 \%$, the ratio between chlorogenic acid and catechin could be used as a screening marker for apricot varieties. Indeed, this parameter was very different among the three cultivars: 0.77 for Ceccona, 0.22 for Pellecchiella and 0.18 for Vitillo.

\section{Materials and methods}

\section{Plant material}

The trial was carried out in 2017 in a private orchard located about $120 \mathrm{~m}$ above sea level (lat. $40^{\circ} 82^{\prime} 54^{\prime \prime}$ Nord, long. $14^{\circ}$ $35^{\prime} 67^{\prime \prime}$ Est), in the National Park of the Vesuvius area (Portici, Naples, Italy), using apricot trees of three autochthonous cultivars with different ripening times: Ceccona (June 8-10), Vitillo (June 16-23) and Pellecchiella (June 23-29). Eighteen-years-old trees were trained to the open vase system, spaced $4.5 \times 3.0 \mathrm{~m}$ (741 trees/ha) and grafted onto Myrabolan $29 \mathrm{C}$. Trees were submitted to the local cultivation practices. In particular, they were regularly fertigated and pests and diseases were kept under control in order to obtain an optimal yield and high quality. All the trees underwent fruit thinning.

For each cultivar, fruit samples were harvested from ten trees in full production by performing two (cv Ceccona) or three (cv Vitillo and cv Pellecchiella) pickings, every third day, covering the whole commercial ripening period. At each sampling, the skin colour was determined by visually measuring the extension of the skin cover colour as a percentage of the whole fruit skin surface and fruits were divided into three classes: cover colour on more than $65 \%$, less than 65 but more than $35 \%$ and less than $35 \%$.

\section{Physico-chemical parameters}

At each picking, 30 fruits per tree were sampled randomly from different parts of the canopy and individually weighed and analysed for flesh firmness (FF), soluble solids content (SSC) and titratable acidity (TA). FF was determined by measuring firmness on two opposite sides in the equatorial zone of the fruit after skin removal using a digital penetrometer (FT 327, Effegi, Milan, Italy) equipped with an $8 \mathrm{~mm}$ tip. The SSC ( ${ }^{\circ} \mathrm{Brix}$ ) of the juice extracted from each fruit was determined using a digital refractometer (HI 96814, Hanna Instruments, Italy), equipped with a temperature compensation system. TA (g malic acid per $100 \mathrm{~g} \mathrm{FW}$ ) was determined by neutralizing fruit juice acids with an alkaline solution $\left(0.1 \mathrm{~mol} \mathrm{~L}^{-1} \mathrm{NaOH}\right.$ ) to a final $\mathrm{pH}$ value of 8.2 (Orion 2-Star Benchtop pH Meter, Thermo Electron Corporation, Waltham, Massachusetts, USA). Dry matter content was estimated by weighing a sample before and after heating at $65^{\circ} \mathrm{C}$ in a forced air draft oven for $12 \mathrm{~h}$ and results are expressed as $g$ dry weight (DW) $g^{-1}$ fresh weight (FW). The measurements of SSC and TA were performed in triplicate ( $n$ $=3$ ) at each picking.

Finally, at commercial harvesting time, 30 fruits were collected and divided into five replicates $(5 \times 6)$. They were then peeled and homogenized for the sub sequential analyses of total antioxidant capacity and polyphenols. The juices were stored at $-80^{\circ} \mathrm{C}$ until analysis.

\section{Antioxidant activity measurements}

Antioxidant activity was measured using the DMPD method as described by Fogliano et al. (1999). The total antioxidant capacity is expressed as $\mu \mathrm{mol}$ Trolox equivalent $\mathrm{g}^{-1} \mathrm{FW}$ (Trolox equivalent antioxidant capacity - TEAC).

\section{Extraction of phenolic compounds for high-resolution mass spectrometry}

Following the method of Cocconi et al. (2016), slightly modified, one gram of freeze-dried puree was diluted in 50 $\mathrm{mL}$ of a water:methanol (50:50, v/v) solution. Each sample was homogenized using an Ultra-Turrax (T25 basic IKA ${ }^{\circledR}$, IKAWerke, Staufen, Germany), sonicated for $10 \mathrm{~min}$, kept for 10 min in a horizontal shaker, filtered with a paper filter (Chemifarm, Parma, Italy) and then with a $0.2 \mu \mathrm{m}$ syringe drive nylon filter unit (Millex-GN Millipore; Bedford, MA, USA). Analyses were carried out in duplicate and each sample was injected two times. Polyphenolic standards, including rutin, catechin, epicatechin, chlorogenic acid and procyandin B2, were purchased from Sigma-Aldrich Chemical Co. (St. Louis, MO, USA). The solvents, HPLC-grade methanol and acetonitrile, were purchased from Carlo Erba reagents (Carlo Erba Reagents, SAS, Chaussée du Vexin, France).

High-resolution mass spectrometry (HRMS, Orbitrap) analysis of polyphenolic compounds from apricot puree

\section{UHPLC analysis}

The qualitative and quantitative profile of phenolic compounds was obtained using a Ultra High Performance Liquid Chromatograph (UHPLC) (Thermo Fisher Scientific, Waltham, MA, USA) equipped with a degassing system, a Dionex Ultimate 3000 Quaternary UHPLC pump working at $1250 \mathrm{bar}$, an autosampler device and a thermostated ( $\mathrm{T}=25$ $\left.{ }^{\circ} \mathrm{C}\right)$ Kinetex $1.7 \mu \mathrm{m}$ Biphenyl $(100 \times 2.1 \mathrm{~mm})$ column. Injection volume was $2 \mu \mathrm{L}$. Eluent phase was formed as follows: phase $A\left(\mathrm{H}_{2} \mathrm{O}\right.$ in $0.1 \%$ formic acid); phase $B$ (methanol in $0.1 \%$ formic acid). All the metabolites were eluted using a $0.2 \mathrm{~mL} \mathrm{~min}^{-1}$ flow rate with a gradient programmed as follows: $0 \mathrm{~min}, 5 \%$ of phase $\mathrm{B} ; 1.3 \mathrm{~min}, 30 \%$ 
of phase $B ; 9.3 \mathrm{~min}, 100 \%$ of phase $B ; 11.3 \mathrm{~min}, 100 \%$ of phase $B ; 13.3 \mathrm{~min}, 5 \%$ of phase $B ; 20 \mathrm{~min}, 5 \%$ of phase $B$.

\section{Orbitrap Q Exactive mass spectrometric analysis}

For mass spectrometric analysis, a Q Exactive Orbitrap liquid chromatograph-tandem mass spectrometer (LC-MS/MS) (Thermo Fisher Scientific) was used. An electrospray ionization (ESI) source (HESI II, Thermo Fischer Scientific) operating in negative ion mode (ESI-) was used for all the phenolic compounds analysed.

Ion source parameters in ESI- mode were: spray voltage $-2.8 \mathrm{kV}$, sheath gas (N2 >95\%) 45, auxiliary gas (N2 >95\%) 15 , capillary temperature $275^{\circ} \mathrm{C}$, S-lens RF level 50 , auxiliary gas heater temperature $305^{\circ} \mathrm{C}$.

The AGC target value was $1 \times 106$ and the resolution was set at $70000 \mathrm{FWHM}$, with a scan rate in the range $100-1000 \mathrm{~m} / \mathrm{z}$ in full MS mode. Analyses were carried out in PRM mode setting the collision energy values (CE) optimized for each compound as reported in Supplementary materials Table 1. The accuracy and calibration of Q Exactive Orbitrap LCMS/MS was checked daily using a reference standard mixture obtained from Thermo Fisher Scientific. Data analysis and processing were performed using Xcalibur software, v. 3.0.63 (Thermo Fisher Scientific).

\section{Statistical analysis}

All biometric data were statistically analysed by three-way analysis of variance (ANOVA) using the SPSS 13 software package (SPSS 13.0 for Windows; SPSS Inc., Chicago, IL). Whenever interactions were significant, a one-way ANOVA was performed. Data from polyphenolic determinations were statistically analysed by one-way analysis of variance (ANOVA) using the same software. To separate treatment means for each parameter measured, Duncan's multiple range test was performed at a significance level of $P \leq 0.05$.

\section{Conclusions}

The genetic variability of apricot cultivars has always led to numerous difficulties in defining univocal fruit quality criteria. In the present study, there were significant differences in the main physical and chemical parameters that define the qualitative profile of apricot fruits and also in their bioactive components, in particular, the total antioxidant capacity and the polyphenol content. All the factors taken into consideration, as cultivar, picking time and skin cover colour, affected all of the qualitative (fruit weight, SSC, FF and TA) and nutritional (polyphenol content and total antioxidant capacity) characteristics of the fruits. Among the Vesuvian apricot cultivars, Pellecchiella performed more satisfactory than the others for most of the parameters considered. A quantification of minor phenolic compounds (hyperoside, kaempherol-3-rutinoside, narcissin and naringenin) is reported for the first time in apricot. Also, for the first time, a dilution effect on TEAC during ripening was shown. This is important because it indicates that, during ripening, the decrease in TEAC is due to fruit growth and there could be a synthesis of compounds that affect TEAC instead of a degradation, as the decrease of TEAC on a per $\mathrm{g}$ basis could suggest.
The significant linear relationships between the percentage of skin cover colour and SSC and FF indicate that the percentage of skin cover colour may be a suitable/powerful harvesting index for apricots, at least for the Vesuvian cultivars and, more in general, for traditional cultivars. This is an important achievement because this parameter is easy to evaluate and the harvesting decision can be made for each individual fruit at each picking. In this regard, it is important to remember that apricot harvesting is normally done in 2-3 pickings.

\section{Acknowledgements}

Authors are grateful to Sister Mary F. Traynor, for her critical revision of the manuscript and for English editing of the final revised draft.

\section{References}

Baldicchi A, Farinelli D, Micheli M, Di Vaio C, Moscatello S, Battistelli A, Walker RP, Famiani F (2015) Analysis of seed growth, fruit growth and composition and phosphoenolpyruvate carboxykinase (PEPCK) occurrence in apricot (Prunus armeniaca L.). Sci Hortic. 186:38-46.

Basile B, Cirillo C, Santin A, Forlani M (2005) Fruit quality of Vesuvian apricots harvested at different ripening stages after a cold-storage period. Acta Hortic. 682:1443-1450.

Bassi D, Selli R (1990) Evaluation of fruit quality in peach and apricot. Adv Hortic Sci. 14:107-112.

Cocconi E, Stingone C, Zanotti A, Trifiro A (2016) Characterization of polyphenols in apricot and peach purees by UHPLC coupled to HRMS Q-Exactive ${ }^{\mathrm{TM}}$ mass spectrometer: an approach in the identification of adulterations. J Mass Spectrom. 51 (9):742-749.

Contessa C, Mellano MG, Beccaro GL, Giusiano A, Botta R (2013) Total antioxidant capacity and total phenolic and anthocyanin contents in fruit species grown in Northwest Italy. Sci Hortic. 160:351-357.

Dauchet L, Dallongeville J (2008) Fruit and vegetables and cardiovascular disease: epidemiological evidence from the non-western world. Brit J Nutr. 99:219-220.

Delwiche MJ, Baumgardner RA (1985) Ground color as a peach maturity index. J Am Soc Hortic Sci. 110 (1):53-57.

Dragovic-Uzelac V, Levaj B, Mrkic V, Bursac D, Boras M (2007) The content of polyphenols and carotenoids in three apricot cultivars depending on stage of maturity and geographical region. Food Chem. 102:966-975.

Drogoudi PD, Vemmos S, Pantelidis G, Petri E, Tzoutzoukou C, Karayiannis I (2008) Physical characters and antioxidant, sugar and mineral nutrient contents in fruit from 29 apricot (Prunus armeniaca L.) cultivars and hybrids. J Agr Food Chem. 56:10754-10760.

ISTAT (2017) Censimento agricoltura 2010. http://daticensimentoagricoltura.istat.it/. (December 2018).

Famiani F, Baldicchi B, Casulli V, Di Vaio C, Cruz-Castillo JG, Walker R P (2017) The occurrence of phosphoenolpyruvate carboxykinase (PEPCK) and enzymes related to photosynthesis and organic acid/nitrogen metabolism in apricot flowers (Prunus armeniaca L.). Acta Physiol Plant. 39:260.

Fideghelli C, Della Strada G (2010) The breeding activity on apricot in the world from 1980 through today. Acta Hortic. 862:93-98. 
Fogliano V, Verde V, Randazzo G, Ritieni A (1999) Method for measuring antioxidant activity and its application to monitoring the antioxidant capacity of wines. J Agr Food Chem. 47:1035-1040.

Guerreri F, Audergon JM, Albagnac G, Reich M (2001) Soluble sugars and carboxylic acids in ripe apricot fruit as parameters for distinguishing different cultivars. Euphytica 117:183-189.

Hegedüs $A$, Engel $R$, Abrankó $L$, Balogh $E$, Blázovics $A$, Hermán R, Halász J, Ercisli S, Pedryc A, Stefanovits-Bányai É (2010) Antioxidant and antiradical capacities in apricot (Prunus armeniaca L.) fruits: variations from genotypes, years, and analytical methods. J Food Sci. 75:C722-C730.

Hegedüs A, Pfeiffer P, Papp N, Abrankó L, Blázovics A, Pedryc A, Stefanovits-Bányai E (2011) Accumulation of antioxidants in apricot fruit through ripening: characterization of a genotype with enhanced functional properties. Biol Res. 44:339-344.

Janatizadeh A, Naderi Boldaji M, Fatahi R, Ghasemi Varnamkhasti M, Tbatabaeefar A (2008) Some post harvest physical properties of Iranian apricot fruit. Int Agrophys. 22:356-363.

Kyriacou MC, Rouphael Y (2018) Towards a new definition of quality for fresh fruits and vegetables, Sci Hortic. 234:463469.

Leccese A, Bartolini S, Viti R (2007) Total antioxidant capacity and phenolics content in fresh apricots. Acta Aliment Hung. 37:65-76.

Leccese A, Bartolini S, Viti R (2012) Genotype, harvest season, and cold storage influence on fruit quality and antioxidant properties of apricot. Int J Food Prop. 15 (4):864-879.

Leccese A, Bureau S, Reich M, Renard MGCC, Audergon JM, Mennone C, Bartolini S, Viti R (2010) Pomological and nutraceutical properties in apricot fruit: cultivation systems and cold storage fruit management. Plant Food Hum Nutr. 65:112-120.
Lo Bianco R, Farina V, Indelicato SG, Filizzola F, Agozzino P (2010) Fruit physical, chemical and aromatic attributes of early, intermediate and late apricot cultivars. J Sci Food Agr. 90:1008-1019.

Luchsinger LE, Walsh CS, Monet R (1998) Development of an objective and non-destructive harvest maturity index for peaches and nectarines. Acta Hortic. 465:679-687.

Madrau MA, Piscopo A, Sanguinetti AM, Del Caro A, Poiana $\mathrm{M}$, Romeo FV, Piga A (2009) Effect of drying temperature on polyphenolic content and antioxidant activity of apricots. Eur Food Res Technol. 228:441-448.

Mattatelli B, Pennone F, Nicotra A, Mezzetti B, Bassi D, Di Vaio C, Guerriero R, Valentini N (2003) Albicocco. In: Sartori A, Vitellozzi F, Grassi F, Della Strada G, Fideghelli C, (eds) II germoplasma frutticolo in Italia, Vol. I - Drupacee, MiPAF, Roma, Italy, pp 23-85.

Mratiniü E, Popovski B, Miloševiü T, Popovska M (2011) Evaluation of apricot fruit quality and correlations between physical and chemical attributes. Czech J Food Sci. 29:161-170.

Piagnani MC, Castellari L, Sgarbi P, Bassi D (2013) Fruit quality evaluation of diverse apricot cultivars. Asp Appl Biol. 119:139-144.

Ruiz D, Egea J (2008) Phenotypic diversity and relationships of fruit quality traits in apricot (Prunus armeniaca L.) germplasm. Euphytica 163:143-158.

Ruiz D, Egea J, Gil MI, Tomás-Barberán FA (2005) Characterization and quantitation of phenolic compounds in new apricot (Prunus armeniaca L.) varieties. J Agr Food Chem. 53:9544-9552.

Scalzo J, Politi A, Pellegrini N, Mezzetti B, Batino M (2005) Plant genotype affects total antioxidant capacity and phenolic content in fruits. Nutrition 21:207-213.

Schmitzer V, Slatnar A, Mikulic-Petkovsek M, Veberic R, Krska B, Stampar F (2011) Comparative study of primary and secondary metabolites in apricot (Prunus armeniaca L.) cultivars. J Sci Food Agr. 91:860-866.

Wang S, Melnyk JP, Tsao R, Marcone MF (2011) How natural dietary antioxidants in fruits, vegetables and legumes promote vascular health. Food Res Int. 44 (1):14-22. 